\title{
Editorial task: a pleasure within
}

\section{Editorial}

Before two years, I became aware about the commencement of Biodiversity International Journal (BIJ), published by MedCrave Group, USA. I got the principal official welcome from article leading group of BIJ to audit an original copy on multi-disciplinary aspects of biodiversity. Afterward, being familiar with the journal's multidisciplinary facets, I began a formal discussion with publication board about the journal's morals, strategy, organization, and terms and conditions. Quickly, I was prevailing to review no less than one manuscript for every month. For a limited capacity to focus time, I highlighted to review something like a few original copies of manuscript a month for BIJ. For a couple of months, I upgraded assessing articles on my expertise such as Biology, Environment, Biodiversity, and Conservation.

Investigating the calculable expeditiousness and quick quickness of whole publication group of BIJ, I was suited in BIJ's Reviewer Board as an Official Reviewer. In the wake of filling in as a committed Reviewer, I got a gigantic chance to be an Associate Editor of BIJ. Considering my earnestness and precision in submitting reviewed articles in stipulated timeframe, I was credited an Associate Editor of BIJ. In the wake of joining as an Associate Editor, I began imparting my insights, perspectives, thoughts, and proposals for the improvement and upliftment of BIJ, among academic network, academicians, researchers, and consultants.

At this moment, I feel respect and upbeat to be a member of BIJ family. As far as anyone is concerned, Biodiversity International Journal (BIJ) is a network peer explored open access journal, intended to quicken distributing, dispersal, and sharing of biodiversity-related information, adds to the development and societal significance of biodiversity. I consider BIJ as one of the most reputed journal, which covers practically all the thriving aspects of biodiversity for example Species Dynamics, Population Ecology, Community Ecology, Habitat and Ecosystem Ecology, Taxonomy and so on.

The journal (BIJ) itself is a signpost and milestone for accomplishing the achievements to feature and combat the challenging areas of biodiversity for the welfare of humankind and development of societal improvement. The arrangement, morals and configuration of BIJ is so clear and explained in a respectful mold that any individual could see even its objectives and recognitions from academic or research network in any edge of the world. BIJ is invested with countless
Volume 3 Issue I - 2019

\section{Hiren B Soni \\ Department of Environmental Science \& Technology (EST), Institute of Science \& Technology for Advanced Studies \&} Research (ISTAR), India

\begin{abstract}
Correspondence: Hiren B Soni, Department of Environmental Science \& Technology (EST), Institute of Science \& Technology for Advanced Studies \& Research (ISTAR), Vallabh Vidyanagar - 388I20, Dist. Anand, Gujarat, India, Tel +9I942602390I/88496|4554, Email drhirenbsoni@gmail.com
\end{abstract}

Received: January 29, 2018 | Published: January 31, 2019

highlights, which has leaded it to the high-rise accomplishment within no time. The purposes behind the most across the board greatness and fantastic acclaim of BIJ incorporates the most effective and skilful article group, affable publication board individuals, relate editors, agreeable and provoke activities of reviewers, relentless stream of pivotal number of original copies from writers of every conceivable corners of the world, and many more.

The BIJ merits every characteristic of being a remarkable journal of worldwide norms attributable to its prominent research quality, fast development of acknowledgment of original manuscripts, tremendous network of writers at worldwide dimension, boundless system, close by free access, and clear organogram of colleagues. The liberal, honorable, and others conscious methodology of publication group towards all the Editorial Board Members, Associate Editors, and Reviewers made me saving, contributing, and giving my time for the advancement and upliftment of BIJ for its earth shattering and immense achievement.

I render my best respects, ecstatic wishes, and hallowed endowments for the triumphant victory and radiant achievement of BIJ among entire academic as well as research network world-over as an esteemed bibliographic access for biodiversity. May the Journal (BIJ) and MedCrave Group, USA, walk towards the magnificent greatness and fantastic accomplishment at worldwide dimension.

\section{Acknowledgments}

None.

\section{Conflicts of interest}

The author declares no conflicts of interest. 